\title{
BUSINESS PERFORMANCE MEASUREMENTS IN ASSET MANAGEMENT WITH THE SUPPORT OF BIG DATA TECHNOLOGIES
}

\author{
Jaime CAMPOS \\ Linnaeus University \\ Pankaj SHARMA \\ IIT Delhi, New Delhi \\ Erkki JANTUNEN \\ VTT Technical Research Centre of Finland \\ David BAGLEE \\ University of Sunderland \\ LUCa FUMAGALLI \\ Politecnico di Milano
}

\begin{abstract}
:
The paper reviews the performance measurement in the domain of interest. Important data in asset management are further, discussed. The importance and the characteristics of today's ICTs capabilities are also mentioned in the paper. The role of new concepts such as big data and data mining analytical technologies in managing the performance measurements in asset management are discussed in detail. The authors consequently suggest the use of the modified Balanced Scorecard methodology highlighting both quantitative and qualitative aspects, which is crucial for optimal use of the big data approach and technologies.
\end{abstract}

Key words: business performance measurements, asset management, big data technologies

\section{INTRODUCTION}

In manufacturing there is a strong need to diminish and eliminate costly, unplanned downtime as well as unexpected breakdowns. Within the manufacturing environment, with growing complexity of equipment and high degree of automation, expectations from maintenance are now growing. In addition, the diversity of data to support maintenance strategy development adds more complexity for data sharing and exchanging. A system-wide communication approach is needed to efficiently process and distribute the data [1]. The emergence of Information and Communication Technologies (ICTs) and the emaintenance approach in the industry has resulted in a promising move from the era of fix when failed into the era of predict and prevent. The move into the latest era is facilitated by the development of sophisticated sensors and Information Communication technologies (ICTs) that are adept to deliver data about the machines health condition, i.e. status and performance. However, according to Lee et al. [2], there is slightly and/or almost no practical use of the existent data that are produced by the machines or other related data that could possibly increase the efficiency of the asset management process. The data produced in a company is extremely important for improved decision making. Performance Measurement is a well-recognized and important area in the manufacturing strategy literature [3]. The maintenance performance measurement is both quantitatively and qualitatively grounded [4]. The quantitative measures are inter alia economic and technical values, statistical and partial maintenance productivity indices. The qualitative measures are mostly the human factors. In the case of asset management, customers form a major part of this qualitative measurement. The qualitative methods complement the quantitative methods in order to present a larger clearer picture of the performance. The data mining and big data technologies provide several "new" opportunities with the emergent algorithms to find hidden patterns on the data that the performance indices are based on. This becomes crucial, since companies that use the latest technologies in an optimal manner can acquire competitive advantages, which is crucial in today's aggressive markets.

Consequently, the paper suggests the use of a modified Balanced Scorecard in conjunction with the Big data and performance measurement process, since it provides a clear connection to the asset management strategy chosen and its objectives. Further, it gives an understanding of the needed Information Systems (IS) and ICTs (in this case the big data technologies) depending on the strategy, objectives and critical success factors.

The current paper is structured in the following way. Section 2 briefly reviews the area of performance measurements and highlights essential characteristics of it in the domain of interest. Next, in Section 3, big data and its relation to the performance indices are discussed. In Section 4, the use of a modified Balanced Scorecard is 
suggested for the strategic management of the ICTs, especially the big data technologies in connection to the domain of interest.

\section{THE PERFORMANCE MEASUREMENTS}

In this section, a discussion on common performance measuring methods is carried out including a brief on the development of Balanced Scorecard. Adaptation of balanced scorecard methodology to measure the performance of maintenance and assets is also discussed in the section.

The authors, Srimai et al. [5] explain the evolutionary paths of performance measurement from the 1980s to the present. Historically, performance measurement has been examined through the prism of financial measures. In the 1970s, researchers examined how organizations used management accounting systems especially budgeting as tools for performance measurement. In the 1980s, the focus was placed essentially on the budgeting process and its impact on performance [6]. Limitations of financial data as the basis for decision making in organisations has been recognised for a long time [7]. Olve et al. [8] emphasized on the need to include non-financial measures in the performance measurement system. Recent literature in this area also suggests that organizations should place more emphasis on non-financial measures in their performance measurement systems; that organizations must use new performance measurement approaches; and that measures should be aligned with contextual factors such as strategy and organizational structure [6].

The field of performance measurement slowly evolved from considering only financial aspects to a more holistic methodology that included non-financial aspects as well, such as the Balanced Scorecard developed by Kaplan and Norton [9]. In addition, Keegan et al. [10] introduced a performance measurement matrix. It aimed at assessing the performance of the organization on financial, nonfinancial, internal and external aspects. Fitzgerald et al. [11] and Azzone et al. [12] also introduced different techniques of performance measurement. Cross and Lynch [13] posited the Strategic Measurement Analysis and Reporting Technique system (SMART). Some other approaches include Integrated Performance Measurement Systems [14], the Performance Prism [15], etc.

In addition, Nonaka [16] argues that performance Indices is not just the connection between performance measures and strategy in an enterprise that is important, but also the knowledge required for the organization to achieve their strategic goals.

The IS/ICTs provides companies with, and in this case maintenance, with many opportunities [17]. Use of IS/ICT'S is also important for the creation, storage, and dissemination of knowledge for the employees' various work tasks. The performance indices are important for the successful accomplishment and control of the enterprises strategic goals $[9,18]$. Pintelon et al. [19] mention that the performance measures are important, this to be able to react in time for threats or opportunities that the company might experience. While Dwight $[20,21]$ mention that they are important for the measurement of the various activities that the enterprise undertakes. Neely et al. [18] says that it is a function of the effectiveness and efficiency of every action the company undertakes, therefore, it is crucial for any company.
In addition, Performance Management is a process by which a company manages its performance [14]. There is evidence to suggest that companies using an integrated balanced Performance Management System perform better than those that do not measure their performance $[22,23]$. Neely [24] posited that the approach of performance measurement must be practically feasible and cost effective. It is important to know what to measure and how to measure. The performance measures are needed to be relevant, interpretable, timely, reliable and valid [25]. Bititci et al. [14] highlighted that performance management of an organization should be "in line with its corporate and functional strategies and objectives".

However, the most widely used method for measuring performance was the Balanced Scorecard. Kaplan and Norton developed Balanced Scorecard as a method to use financial as well as non-financial data for informed decision making by the managers [9]. Balanced Scorecard for performance measures provides an insight into four management perspectives, i.e. financial, internal business processes, customer perspective and innovation \& learning, which separately and together show the benefits of linking long term strategic objectives with short term actions [9]. It provides support to reach a decision whether or not the activities of the organization/department are aiding in meeting the objectives in line with the company's strategy or vision. The choice of non-financial data points is made with strategic considerations in mind.

Lawrie and Cobbold [26] listed the important attributes of a scorecard which are the following, i.e. it is a mixture of financial and non-financial measures, a limited number of measures, measures are clustered into four groups called perspectives, originally called "Financial", "Customer", "Internal Process" and "Innovation and Learning". The last two were renamed "Internal Business Process" and "Learning and Growth" in Kaplan and Norton [27]. The measures are chosen to relate to specific strategic goals. The different measures should be chosen in a way that they gain the active endorsement of the senior management of the organization where some of the measures attempt to represent causality.

The 1st generation balanced scorecard struggled in application because of vague definitions. There were design challenges that limited its usage. There were problems resulting because of adverse effects of poor measure selection. The common problem being encountered was of filtering the measures and classifying them in clusters. There was no clarity on the measure selection process in the initial literature on balanced scorecards. In the 2nd generation balanced scorecards, Kaplan and Norton [28] addressed the issues of vagueness by introducing 'strategic objectives in each of the cluster/perspective. Newing [29] added the concept of causality. Further work during this period moved from defining causal relations between the clusters/perspectives, strategic objectives and performance measures. However, the problems of correctly identifying the causal relations that spanned over the clusters started emerging. There were additional problems of determining the correct composition of people who will decide the strategic objectives. The key issue remained of building confidence in the methodology to somehow indicate that the balanced scorecard reflects the strategic objectives of the organization [26]. This key issue was addressed by adding 'vision' or 'destination statements' in the 3rd generation of balanced scorecards. In the earlier literature, 
these destination statements were created after the design of balanced scorecard was complete. This statement was made to reflect the likely impacts of the objectives that were chosen. These statements acted as reference points while the organisations were in the process of pursuing the strategic objectives. Kotter [30] argued that it is easier to arrive at objectives and measures if a vision statement is available ab-initio. This led to a change in the balanced scorecard methodology and preparation of 'destination statement' became the first step in the process.

Wide applicability of balanced scorecard method has prompted researchers to use it for assessing performance of other functions. Maintenance performance measurement (MPM) is one such usage of the method. Parida and Kumar [31] have listed the factors for demand of MPM, such as measuring value created by the maintenance, justifying investment, revising resource allocations, health safety and environmental (HSE) issues, focus on knowledge management, adapting to new trends in operation and maintenance strategy, organizational structural changes, etc.

Moreover, a major part of any performance management system is the measurement of the performance of the assets. Societal responsibilities for prevention of loss of life and injuries, besides high maintenance cost are compelling the management to undertake Asset Performance Assessment (APA) as part of the business management and measurement system. Different APA frameworks need to be developed in line with the "Balanced Scorecard" [27] to ensure that all operational and maintenance activities of the assets are aligned to the organization's corporate strategies and objectives in a balanced manner [32]. A Multi-criteria hierarchical APA framework for Engineering Asset has been developed by Parida and Chattopadhyay [33]. This framework makes use of both financial and non-financial measures to assess the asset performance. It includes seemingly intangible items including customer and employee satisfaction in addition to financial factors including Return on Investment (Rol). The framework provides a measure of the asset performance of the organization.

Consequently, global organizations have realized the importance and necessity of a good performance management system. The efficacy of these management systems can be drastically improved through use of big data analytics. In the next section of the paper, big data analytics and its characteristics as applicable to performance management are discussed.

\section{BIG DATA AND PERFORMANCE MEASUREMENTS IN ASSET MANAGEMENT}

In this section, the Big data approach for measurement of performance indices is discussed. The shift of the performance measurement techniques from pure financial data to a mix of financial and non-financial data increased the subjectivity of the measurement system. There have been continuous improvements in the measurement system such that the subjectivity of intangible data can be reduced. The three generations of balanced scorecards have aimed at achieving more objectivity in the measures by removing vagueness through introduction of strategic objectives and destination statements [26]. Increased data inputs from customers and employees through techniques of crowd-sourcing have improved the efficiency of the measurement systems. Big data analytics has the potential to make the measurement systems even better.

Big data has two important characteristics; high dimensionality and large sample size. High dimensionality of the data helps in accurately predicting the future [34]. On the other hand, a large sample size helps the analysis in two ways; firstly, exploring the hidden structures of each sub-population of the data, which is traditionally not feasible and might even be treated as 'outliers' when the sample size is small; and secondly, extracting important common features across many sub-populations even when there are large individual variations [35].

Large volumes of heterogeneous data is another characteristic of big data. The same type of data can be represented in different forms, depending on the choice made by different organizations. The data is collected through autonomous data sources with distributed and decentralized controls. Being autonomous, each data source is able to generate and collect information without involving (or relying on) any centralized control. The complexity and the relationships underneath the data are also increasing as the data is becoming big. In an early stage of data centralized information systems, the focus is on finding best feature values to represent each observation [36].

The major portion of the data that constitutes big data is from the social media and the internet. The social media and Internet contain large amount of information on the consumer preferences and confidences, leading economic indicators, business cycles, etc. It is anticipated that the social network data will continue to explode and be exploited for many new applications [35]. To summarize, big data has the characteristics of heterogeneous data which has high dimensionality and large sample size, collected by autonomous and decentralized sources that is used for exploring complex and evolving relationships between variables. In the next section, the paper discusses the applicability of these features of big data to performance measurement of organizations.

Performance management systems are a holistic system of measuring the performance of an organization. They base the measurement on financial, non-financial, external and internal factors. The data is gathered from a host of different sources that vary from figures to tweets. These data sources are autonomous with no centralized control. Customers that are located on all parts of the globe key in the feedbacks through twitter, Facebook, product review sites, complaints on the internet, to name a few amongst many other methods. Most of this data is through subjective comments, though some of it may be in terms of ranking on point scale. This constitutes a large part of big data that can be analysed. In addition to the customers, employees pitch in with more data through written suggestions, complaints and feedbacks. Each member of the organization and its customers act as sensors that are sending in data into the management system. The data from maintenance department gets added to it too. There are often complex relationships that exist between the data points that get highlighted because of the large volume of data coming into the system. This is very similar to big data analytics and has similar characteristics that were discussed previously in this section 4 . The data collection and analysis part in asset management scenario is depicted as framework in Figure 1. 


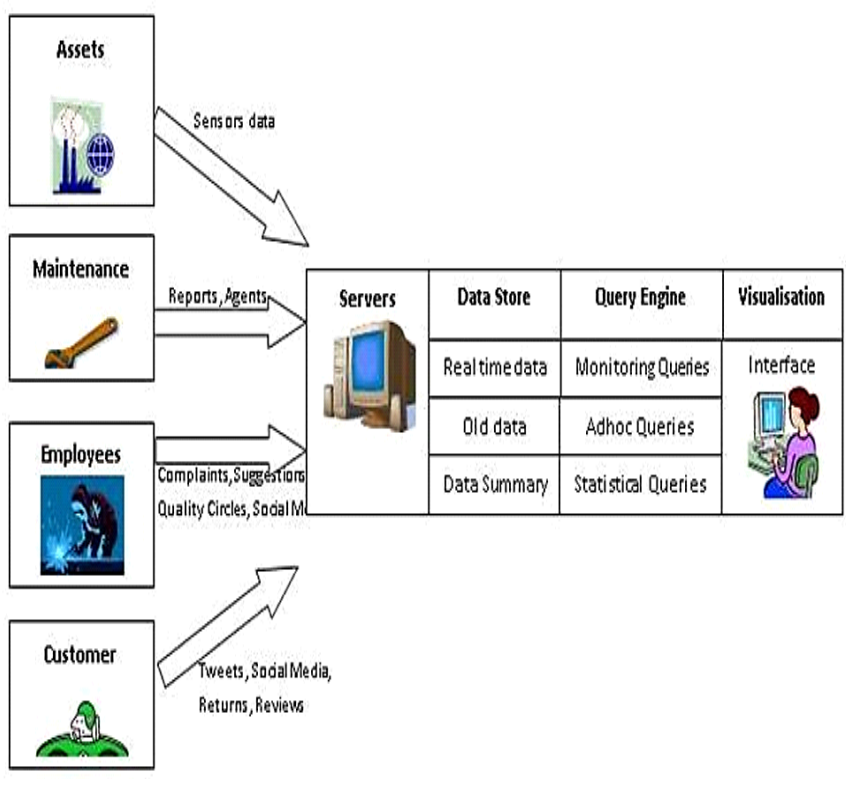

Fig. 1 Performance Management through Big Data

Source: Adapted from Jagadish et al. [36]

The data in the storage is of three different types; real time data, old data and summary of the data. Real time data is used to monitor the condition of the assets, quality of the products, reaction of the customers to new launches, morale of the employees, etc. Old data and the summary of the data are used to answer statistical queries that indicate trends which can foretell future. An important part of this performance management system is the way the final results are presented to the user. It has to be made sure the end points - humans - can properly "absorb" the results of the analysis and not get lost in a sea of data [37].

It is important when working with big data to keep in mind the quality of data and quality of models that are developed. For example, it is clear from statistics that most people die in horizontal position i.e. in bed. From this, it could be wrongly concluded that the easiest way to guarantee a long life would be avoiding horizontal position and in order to do so to buy a bed in which one can sleep in vertical position. Another example is how eating ice-cream correlates with drowning accidents. In maintenance the running hours are often collected and based on those statistical studies are carried out in order to optimize the interval for maintenance. Unfortunately, the running hour is a very poor measure of the condition of production machinery because the loading of the machinery is actually a more important factor. Consequently, it is important whenever big data is used to be able to understand the process that is monitored and to realize what should be measured and how this information can be integrated to provide meaningful results.

\section{MANAGING THE PERFORMANCE MEASUREMENTS WITH THE SUPPORT OF THE BIG DATA TECHNOLOGIES}

The decision of selection of a suitable performance measurement can vary depending on the industry, organization and business unit. The implementation methodology of a performance measurement system can also vary depending upon recommendation, frameworks, systems and inter-organizational performance measurement [38]. However, selection of suitable ICTs, especially the big data technologies, that will support the decision making process for the specific performance measurement is an important activity. It is, therefore, crucial to have an understanding of the big data, machine learning and data mining technologies to be able to develop big data systems that provide the right recommendations to the person that will take the decisions. Consequently, the complex picture of all the involved factors that matter both technically as well as financially can be understood by the use of the model shown in Figure 2. Since both technological as well as business aspects of a system are considered, the model can be seen as a more accurate version. The figure highlights the importance of choosing a clear asset management strategy with well laid out mission and vision statements. The selected mission and vision are connected to certain objectives that need to be measured and/or controlled. From this flow out the actions that need to be taken in order to achieve the objectives. These actions are called as Critical Success Factors (CSF). The actions need to be continuously supported with the right and proper Information Systems (IS) and ICTs for their successful implementation.

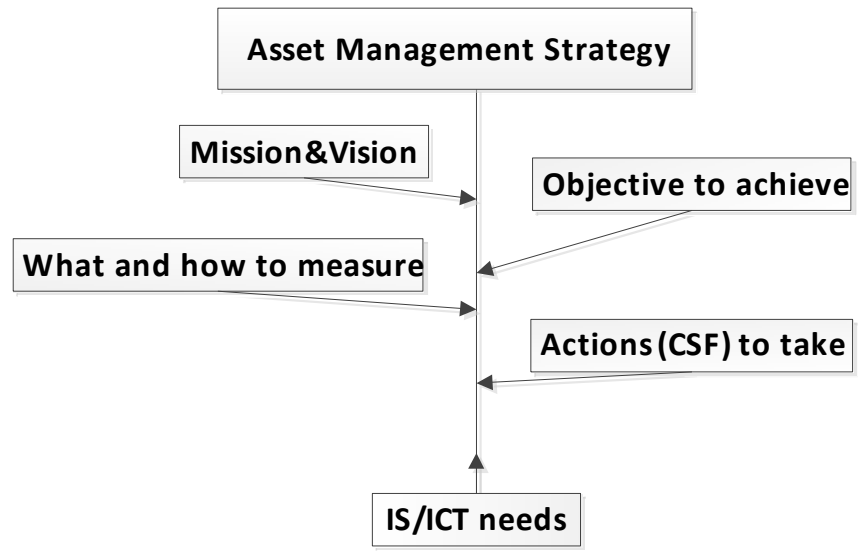

\section{Fig. 2 Strategy and IS/ICT alignment}

The model in Figure 2 is inspired by the DIKAR model [39], which highlights the Data, Information, Knowledge, Action, and Results in a system and uses the well-known Balanced Scorecard (BSC) as a part of the model such that the strategy chosen is in balance with both qualitative and quantitative aspects. The IS and ICTs that are selected must be capable of capturing the data and converting it to information and knowledge. The actions taken and the results that are achieved should ultimately support the fulfilment of business strategy. The ICT needs are the technical support of the system, i.e. the infrastructure that supports the information system in the organization, such as, databases, servers, applications servers, cloud computing, user interfaces, etc. The BSC tries to provide to executives with a framework that is able to translate a company's vision and strategy to some coherent set of performance measures.

Table 1 is a modified version of the conventional balanced score card developed at the Harvard Business School [27, 40]. The four aspects highlighted are the internal business perspective, the financial perspective, the customer perspective and the learning and growth perspective. The aim is to achieve a balance between the different long and short term objectives, outcomes desired and the performance indicators/drivers of those outcomes and between hard objective measures; all aimed to achieve an integrated strategy. 


\begin{tabular}{|c|c|c|c|}
\hline \multicolumn{4}{|c|}{ Internal business/financial/customer/Innovation and learning perspective } \\
\hline Objective to achieve & Measure(s) & Action (CSF) & IS/IT needs \\
\hline $\begin{array}{l}\text { Efficient Mainte- } \\
\text { nance } \\
\text { Process }\end{array}$ & $\begin{array}{l}\text { OEE } \\
\text { Availability } \\
\text { Failures } \\
\text { Planned Stoppages } \\
\text { Quality Losses } \\
\text { Speed Losses }\end{array}$ & $\begin{array}{l}\text { RCM } \\
\text { Improvement } \\
\text { in Communication } \\
\text { Improved Feedback Sys- } \\
\text { tem }\end{array}$ & $\begin{array}{l}\text { Maintenance Performance Measurement } \\
\text { Platform in a Big Data scenario with capabili- } \\
\text { ties to: } \\
\text { - Distribute and store the data files over } \\
\text { different nodes using HDFS, } \\
\text { - Manage Resources with application like } \\
\text { Yarn, }\end{array}$ \\
\hline $\begin{array}{l}\text { Improved } \\
\text { Financial Indicators }\end{array}$ & $\begin{array}{l}\text { Cost of maintenance } \\
\text { per unit } \\
\text { Costs of failures } \\
\text { Cost of lost production }\end{array}$ & $\begin{array}{l}\text { Optimization } \\
\text { of Maintenance } \\
\text { Tasks }\end{array}$ & $\begin{array}{l}\text { - Analyse CSV data (Financial data) } \\
\text { through applications like Hive, } \\
\text { - Analyse sensor data with applications } \\
\text { like Sandbox, Splunk, }\end{array}$ \\
\hline $\begin{array}{l}\text { Satisfied } \\
\text { Customers }\end{array}$ & $\begin{array}{l}\text { High Service level } \\
\text { MTBF } \\
\text { MTTR } \\
\text { Quality Rate } \\
\text { Feedback through } \\
\text { social media }\end{array}$ & $\begin{array}{l}\text { Good Quality Spare Parts } \\
\text { Training and up-skilling } \\
\text { of workforce } \\
\text { Motivated workforce }\end{array}$ & $\begin{array}{l}\text { - Analyse live streaming data (tweets, } \\
\text { complaints, reviews, feedbacks, etc.) } \\
\text { with applications like Solr, MongoDB, } \\
\text { - Visualize analysis and results with Tab- } \\
\text { leau etc. }\end{array}$ \\
\hline $\begin{array}{l}\text { Better Innovation } \\
\text { and Learning }\end{array}$ & $\begin{array}{l}\text { Relations with OEM, Research } \\
\text { Centres etc. } \\
\text { Implementation of advanced } \\
\text { maintenance methods }\end{array}$ & $\begin{array}{l}\text { Investments } \\
\text { in R\&D }\end{array}$ & \\
\hline
\end{tabular}

Source: modified [40].

It means that the balance scorecard and its four perspectives aim to fulfil the company's strategy as best as it is possible. The balance scorecards (BSC) base the development of the key performance indicators (KPI) through the translation of the strategic vision and mission into a set of objectives, from which the business unit, i.e. in this case the asset management department, identifies its Key Success Factors (KSF) or Critical success factors, which then are translated into a series of quantitative KPIs.

It is important to understand connections between these factors. For the internal business in asset management, the objective is to improve the efficiency of the maintenance process. Various measures that indicate the efficacy of the maintenance process are the Overall Equipment Effectiveness (OEE), availability of machines for production, Unplanned and planned stoppages, losses in quality and speed of production. The efforts should be focussed towards improving the efficacy by measuring the performance of the internal process. This can be achieved by implementing Reliability Centered Maintenance (RCM) and improvements in feedback and communication system can improve the maintenance process.

Financial data of the asset management company will be collected and stored in spreadsheets as Comma Separated Values (CSV). These spreadsheets will have measures like cost of maintenance per unit, cost of failures and cost of lost production. These costs can be brought down by optimizing the maintenance process.

Customer satisfaction is measured through Mean Time between Failures (MTBF), Mean Time to Repair (MTTR), the quality rate of the manufactured item and the service levels provided to the operations sub-department by the maintenance teams. The operations sub-department is the customer for the maintenance sub-department in a manufacturing company. The satisfaction level can be improved by using quality spare parts and highly trained motivated workforce. However, the social media feedbacks of the end-customers (those who finally buy the product from the company) can also act as a measurement criteria for the maintenance personnel. Most of this data is unstructured which normally can be found on customer feedback about the products. As the data is unstructured, there is a need to use big data as well as data mining technologies to be able to elicit information and knowledge and/or even hidden patterns from the data. In addition, in asset management it could be interesting to understand the customer complaints and the association with other important attributes, for instance to avoid specific complaints with the products. It is essential to use this technique for data analytics as the information contained in reviews, tweets, complaints, etc. is unstructured. Various methods of text mining such as information extraction, sentiment analysis, question answering, etc., are used to extract structured information from the unstructured data. Employee and customer complaints, customer reviews in the form of Facebook comments or tweets, etc., are some of the unstructured data that falls in this category. The data may, on analysis, reveal the problems in manufacturing process. It is anticipated that the social network data will continue to explode and be exploited for many new applications [35].

Improved Innovation and learning in the asset management department can be ensured through increased investments in R\&D leading to higher collaborations between Original Equipment Manufacturers (OEM) and research centres.

The ICTs needed for this kind of analysis are the data mining and big data analytics, such as association or clustering, since they provide knowledge about hidden patterns. In these approaches there is no response variable that we are trying to find relationship with as in supervised approach, since in the unsupervised method it is like 
working blind, due to the fact that it is possible to understand relationship between variables and observations. Subsequently, better condition monitoring systems that inform about the health of the machine in connection to the faults are required to improve the whole maintenance process. The big data technologies that can be used in this case are the ones that provide diagnosis of the say, bearing fault. There are some researches that have performed clustering for diagnosis of rolling element bearing, which can be found on Wang et al. [41]. The clustering algorithm used was K-means clustering. Similar advanced maintenance techniques are available that deal with numerous other failure modes.

However, the major portion of the data that constitutes big data is from the social media and the internet which is connected to the customer's aspects of the Balance Scorecard perspective. Social media and Internet contain massive amounts of information on the consumer preferences and confidences, leading economic indicators, business cycles, etc. It is important to utilize these inputs in a performance measurement system in order to attain competency and efficiency in the maintenance process.

\section{CONCLUSIONS}

The strategic management and in this case the asset management strategies need a proper alignment with the appropriate IS/ICTs applications portfolio, which is a crucial factor for any company that wants to gain a competitive edge over its rivals. Consequently, the IS/ICTs should be a support for the chosen strategy and should provide the decision maker with the right information and knowledge to be able to take the right decisions resulting in the successful realization of the strategy. The modified BSC supports the former mentioned, since it provides a holistic view as well as a detailed picture of both technical and business needs of a company following an asset management strategy. The business performance measurements part of the modified BSC facilitates the follow up of various metrics and by doing so, strategic failures are avoided. The modified BSC provides a clear connection with the objectives, measurements, actions and the IS/ICTs required for each one of the objectives connected to the strategy. The use of the proposed model or similar approaches highlights existing flaws and increases the alignment between the business and its IS/ ICTs. The work is especially helpful to the organizations that are in the process of deciding to implement a big data analytics based performance measurement system. It provides a formal stepwise methodology that eases the process of decision making. However, there is need to further research the customization issues for particular industries when this method is applied. There will be certain more modifications required for different industry sectors and organizations. Future research can address this issue.

\section{REFERENCES}

[1] D. Baglee, M. Knowles and S. Kinnunen, "A Proposed Maintenance Strategy for a Wind Turbine Gearbox Using Condition Monitoring Techniques", International Journal of Process Management and Benchmarking, vol. 6, no. 3, pp. 386-403, 2016.

[2] J. Lee, J. Ni, D. Djurdjanovic, H. Qiu and H. Liao, "Intelligent prognostics tools and e-maintenance",
Computers in Industry, vol. 57, no. 6, pp. 476-489, 2006.

[3] T. Taticchi, F. Tonelli and L. Cagnazzo, "Performance Measurement and Management: A Literature Review and a Research Agenda", Measuring Business Excellence, vol. 14, no. 1, pp. 4-18, 2010.

[4] U. Kumar, D. Galar, A. Parida, C. Stenström and L. Berges, "Maintenance performance metrics: a state of the art review", Journal of Quality in Maintenance Engineering, vol. 19, no. 3, pp. 233-277, 2013.

[5] S. Srimai, J. Radford and C. Wright, "Evolutionary paths of performance measurement", International Journal of Productivity and Performance Management, vol. 60, no. 7, pp. 662-687, 2011.

[6] M. Gosselin, "An empirical study of performance measurement in manufacturing firms", International Journal of Productivity and Performance Management, vol. 54, no. 5/6, pp. 419-437, 2005.

[7] J. Dearden, "The case against ROI control", Harvard Business Review, vol. 47, no. 3, pp. 124-135, 1969.

[8] N. Olve, J. Roy and M. Wetter, Performance Drivers: $A$ practical guide to using the balanced scorecard. Chichester: John Wiley and Sons, 1999.

[9] R.S. Kaplan and D.P. Norton, "The Balanced Scorecard - Measures That Drive Performance", Harvard Business Review, vol. 70, no. 1, pp. 71-79, Jan-Feb 1992.

[10] D.P. Keegan, R.G. Eiler and C.R. Jones, "Are your performance measures obsolete?", Management Accounting, vol. 70, no. 12, pp. 45-50, 1989.

[11] L. Fitzgerald, R. Johnston, T.J. Brignall, R. Silvestro and C. Voss, Performance Measurement in Service Businesses. London: CIMA, 1991.

[12] G. Azzone, C. Masella and U. Bertelè, "Design of performance measures for time-based companies", International Journal of Operations \& Production Management, vol. 11, no. 3, pp. 77-85, 1991.

[13] K.F. Cross and R.L. Lynch, "The SMART way to sustain and define success", National Productivity Review, vol. 8, no. 1, pp. 23-33, 1998.

[14] U.S. Bititci, A.S. Carrie and L. McDevitt, "Integrated performance measurement systems: a development guide", International Journal of Operation and Production Management, vol. 17, no. 5, pp. 522-534, 1997.

[15] A. Neely, C. Adams and M. Kennerley, The Performance Prism: The Scorecard for Measuring and Managing Business Success. London: Prentice Hall Financial Times, 2002.

[16] I. Nonaka, Harvard Business Review on Knowledge Management, Harvard Business School Press, 1991.

[17] L. Pintelon, N. Du Preez and F. Van Puyvelde, "Information technology: opportunities for maintenance management", Journal of Quality in Maintenance Engineering, vol. 5, no. 1, pp. 9-24, 1999.

[18] A. Neely, J. Mills, K. Platts, H. Richards, M. Gregory, M. Bourne and M. Kennerley, "Performance measurement system design: developing and testing a process based approach", International Journal of Operations \& Production Management, vol. 20, no. 10, pp. 11191145, 2000.

[19] L. Pintelon and F. Van Puyvdelde, "Maintenance Performance Reporting Systems: Some Experiences", Journal of Quality in Maintenance Engineering, vol. 3, no. 1, pp. 4-15, 1997. 
[20] R.A. Dwight, "Searching for Real Maintenance Performance Measures", Journal of Quality in Maintenance Engineering, vol. 5, no. 3, pp. 258-75, 1999.

[21] R.A. Dwight, "Concepts for measuring maintenance performance", in New Developments in Maintenance: An International View, H.H. Martin, Ed. Utrecht: Moret Ernst \& Young Management Consultants, 1995.

[22] M. Kennerley and A. Neely, "Measuring performance in a changing business environment", International Journal of Operations and Production Management, vol. 23, no. 2, pp. 213-229, 2003.

[23] J.H. Lingle and W.A. Schiemann, "From balanced scorecard to strategy gauges: Is measurement worth it?", Management Review, vol. 85, no. 3, pp. 56-62, 1996.

[24] A. Neely, "The performance measurement revolution: why now and where next", International Journal of Operation \& Production Management, vol. 19, no. 2, pp. 205-228, 1999.

[25] U. Al-Turki and S. Duffuaa, "Performance measures for academic departments", International Journal of Educational Management, vol. 17, no. 7, pp. 330-338, 2003.

[26] G. Lawrie and I. Cobbold, "Development of the 3rd Generation Balanced Scorecard. Evolution of the Balanced Scorecard into an effective strategic performance management tool", 2GC Active Management, Maidenhead, Berkshire, UK, 2002.

[27] R.S. Kaplan and D.P. Norton, The Balanced Scorecard: Translating Strategy into Actions, Boston (MA): Harvard Business School Press, 1996.

[28] R.S. Kaplan and D.P. Norton, "Putting the Balanced Scorecard to Work", Harvard Business Review, vol. 71, no. 5, pp. 134-147, Sept-Oct. 1993.

[29] R. Newing, "Wake Up to the Balanced Scorecard!", Management Accounting, vol. 73, no. 3, 1995.

\section{Dr. Jaime Campos}

\section{Associate Professor in Informatics}

Linnaeus University, Faculty of Technology

Department of Informatics

SE-35195 Växjö, SWEDEN

e-mail: Jaime.Campos@Inu.se

\section{MTech. Pankaj Sharma}

Mechanical Engineering Department, Indian Institute

of Technology Delhi, New Delhi 110016 INDIA

e-mail: Pankajtq@gmail.com

\section{D.Sc. Erkki Jantunen}

VTT Technical Research Centre of Finland Ltd.

P.O. Box 1000, FI-02044 VTT, FINLAND

e-mail: Erkki.Jantunen@vtt.fi

\section{Dr. David Baglee}

Reader in Advanced Maintenance.

Faculty of Engineering and Advanced Manufacturing

University of Sunderland, St Peters Campus

Sunderland SR6 ODD, UNITED KINGDOM

e-mail: David.Baglee@sunderland.ac.uk

\section{Dr Luca Fumagalli}

Department of Management, Economics and Industrial Engineering

Politecnico di Milano

Piazza Leonardo da Vinci, 32, 20133 Milano, ITALY

e-mail: luca1.fumagalli@polimi.it
[30] J.P. Kotter, "Leading Change: Why transformation efforts fail?", Harvard Business Review, vol. 73, no. 2, pp. 59-67, Mar-Apr. 1995.

[31] A. Parida and U. Kumar, "Maintenance performance measurement (MPM): issues and challenges", Journal of Quality in Maintenance Engineering, vol. 12, no. 3, pp. 239-251, 2006.

[32] A. Parida, "Asset Performance Assessment", in Asset Management. The State of the Art in Europe from a Life Cycle Perspective, T. Van der Lei, P. Herder and Y. Wijnia, Eds. Houten: Springer Netherlands, 2013, pp. 101-113.

[33] A. Parida and G. Chattopadhyay, "Development of Multi-Criteria Hierarchical framework for Maintenance Performance Measurement (MPM)", Journal of Quality in Maintenance Engineering, vol. 13, no. 3, pp. 241-258, 2007.

[34] J. Fan and Y. Fan, "High dimensional classification using features annealed independence rules", Annals of Statistics, vol. 36, no. 6, pp. 2605-2637, 2008.

[35] J. Fan, F. Han and H. Liu, "Challenges of Big Data analysis", National Science Review, vol. 1, no. 2, pp. 293314, 2014

[36] X. Wu, X. Zhu, G-Q. Wu and W. Ding, "Data Mining with Big Data", IEEE transactions on knowledge and data engineering, vol. 26, no. 1, pp. 97-107, 2014.

[37] H.V. Jagadish, J. Gehrke, A. Labrinidis, Y. Papakonstantinou, J.M. Patel, R. Ramakrishnan and C. Shahabi, "Big Data And Its Technical Challenges", Communications Of The ACM, vol. 57, no. 7, pp. 86-94, 2014.

[38] P. Folan and J. Browne, "A Review of Performance Measurement: Towards Performance Management", Computers in Industry, vol. 56, no. 7, pp. 663-680, 2005.

[39] N. Venkatraman and J.C. Henderson, "Business platforms for the 21st Century", in Mastering Information Management, D.A. Marchand, T.H. Davenport and T. Dickson, Eds. Harlow (FT): Prentince Hall, 2000.

[40] L. Ward and J. Peppard, Strategic planning for information systems. Chichester: Wiley, 2002.

[41] G. Wang, C. Liu and Y. Cui, "Clustering diagnosis of rolling element bearing fault based on integrated Autoregressive/Autoregressive Conditional Heteroscedasticity model", Journal of Sound and Vibration, vol. 331, no. 19, pp. 4379-4387, 2012. 